\title{
Design of Tubular Azimuth Gamma Ray Logging Tool
}

\author{
Jing Yang \\ Beijing Hengtai Wanbo Petroleum Technology Co., Ltd, Beijing, China \\ Email: 13581827210@163.com
}

How to cite this paper: Yang, J. (2016) Design of Tubular Azimuth Gamma Ray Logging Tool. World Journal of Engineering and Technology, 4, 1-8.

http://dx.doi.org/10.4236/wjet.2016.43D001

Received: April 18, 2016

Accepted: October 13, 2016

Published: October 20, 2016

\begin{abstract}
On the Gamma ray reception study, this paper presents the heavy metal shielding method, which is using $\mathrm{C}$ type heavy metal to shield Sodium iodide scintillation crystal. By rotating the drilling tools to scan and detect the gamma ray which are around the borehole wall formation, On study of angle measurement study, base on accelerometers and fluxgate sensors to design the algorithm which can confirm the detecting instrument measurement window position; Moreover, the paper also presents the Rock formation identification method, which is using changing tendency and sequencing of high side and low side gamma to decide the position of the drilling tool. Field experiments showed that the tool can effectively identify the reservoir and rock formation.
\end{abstract}

\section{Keywords}

Azimuth Gamma Ray Logging Tool, Heavy Metal Shielding, Dynamic

\section{Introduction}

Natural gamma ray logging is one of the nuclear logging technique, and it can evaluate rock formation and identify lithology by detecting radiation gamma-ray intensity of different formations and lithology. The measurement results of conventional natural gamma ray logging are the average response to the formation of radioactivity, therefore there is time delay in discriminating the lithology and it can't distinguish interface features between upper and lower lithologic and find reservoir timely [1]. Azimuth gamma ray logging tool makes technological innovation against conventional Gamma Ray logging tool's non-direction. It detects gamma radioactivity of rock formations by two or more separate sensors in different directions, and decides drilling tool's position by rock formation identification method. This technique is particularly suitable for directional wells, horizontal wells, extended reach wells and branch wells and other difficult 
process of thin oil wells, which can greatly improve the efficiency of drilling and oil recovery [2].

At present, the existing azimuth gamma ray logging tools of domestic and overseas mainly take advantage of more than one detectors which are equally divided in perpendicular to the axial direction on the drill collar and processed separately [3] [4]. Therefore, it's difficult to install and repair the instrument. Moreover, it greatly increases the expense due to multiple detectors and the corresponding post-processing circuits. So this paper proposed a new scheme which use only one gamma detector in a scanning way to measure azimuth gamma ray, and designed a tubular azimuth gamma ray logging tool.

\section{The Measuring Principle and Performance Indicators}

\subsection{Principle of Gamma Ray Detector}

Gamma ray detector is mainly made of sodium iodide scintillation crystal, photomultiplier tubes, high voltage power supply and the receiving circuit. Natural gamma ray light into sodium iodide scintillation crystal, and are converted to a specific wavelength light which can be received by photomultiplier tube, by the photomultiplier tube the light become the electronic pulses, finally, receiving circuit records and counts the electronic pulses.

\subsection{Principle of Azimuth Gamma Detector}

Azimuth Gamma ray logging tool puts the $C$ type heavy metal shielding case into the sodium iodide scintillation crystal; the opening angle is 60 degree, leaving a long and narrow gamma measurement window on horizontal axis which only lets gamma ray pass; In perpendicular to the axial direction, install two pairs of orthogonal fluxgate sensors and MEMS accelerometers, and the X-axis consist with the center of the measurement window; When drilling tool rotating, it measures the angle between measurement window and acceleration of gravity in angular transducer to determine the position of the window, From this, the high side and low side gamma ray can be judged. The structure of the detector is shown in Figure 1.

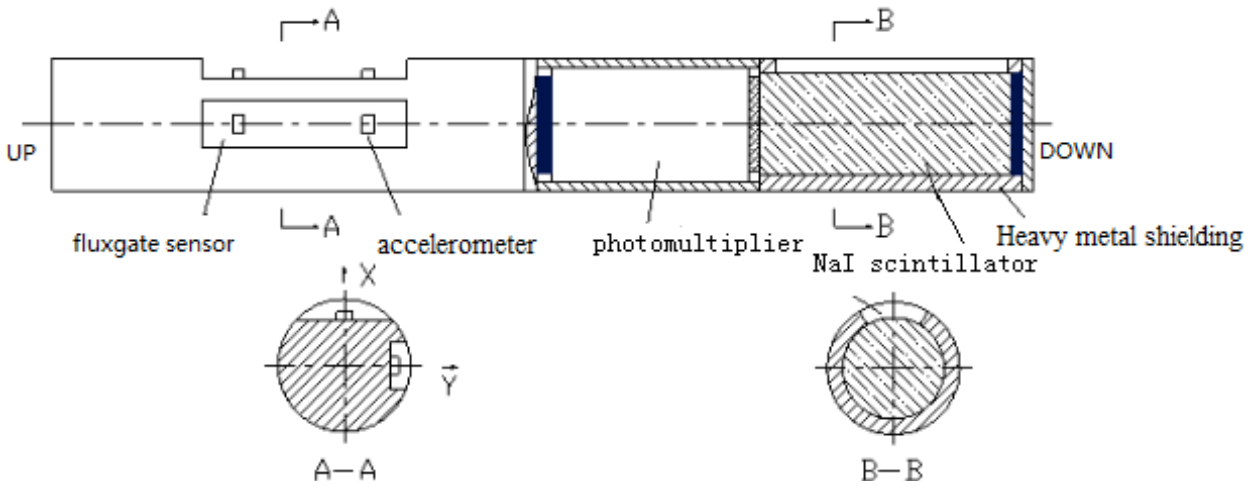

Figure 1. Structure diagram of tubular Azimuthal gamma ray detector. 


\section{The Arithmetic of Measurement Window Position}

Commonly, people judge the posture of an object based on geographic coordinate system, namely the three dimensional coordinate system includes geographical east, geographical north and gravity vector direction, when judging the high side and low side of measurement window position, the gravity vector can be used as a static reference position. In mechanical structure design, the $\mathrm{X}$-axis of angel sensor is bound to the center line of measurement window, so that the angel between measurement window and gravity vector is just the angle between $\mathrm{X}$-axis and gravity vector, namely the gravity tool face angle $\alpha$. $\alpha$ can be calculated as in

$$
\alpha=\arctan \left(\frac{G y}{G x}\right)
$$

$G X$ is the gravity acceleration component of X-axis, $G y$ is the gravity acceleration component of $\mathrm{Y}$-axis, and the unit is $\mathrm{g}$.

Azimuth gamma ray logging tool is working while the drilling tool and gamma detector is dynamic rotating. In generally, the drilling rate of drill tool is not less than 50 RPM, acceleration sensor can't ensure the measurement accuracy because of the influence of vibration, centrifugal force and centripetal force. So the magnetic sensor can be used to get the position of measurement window indirectly. Angle between $\mathrm{X}$ axis and the geomagnetic vector is magnetic tool face angle $\beta$ which can be calculated as in

$$
\beta=\arctan \left(\frac{H y}{H x}\right)
$$

$\mathrm{Hx}$ is the $\mathrm{X}$-axis geomagnetic component, $\mathrm{Hy}$ is the $\mathrm{Y}$-axis geomagnetic components, and the unit is Gauss.

Determining the position of measurement window is divided into two processes which are confirming the angle $\gamma$ between the geomagnetic vector and the gravity vector and confirming the angle a between the measurement window and the gravity vector. For a single drill pipe's drilling time, the orientation of the drilling tool changes slightly, so it is considered that the projection angle $\gamma$ of the geomagnetic vector and the gravity vector is a fixed value in the radial section of the instrument, as in:

$$
\gamma=\alpha-\beta
$$

The projection angle $\gamma$ corresponds to the projection of an acute angle in a plane, and its data range is $\left[0^{\circ}, 180^{\circ}\right]$, so $\gamma$ needs to be adjusted in the software. During the rotation of drilling tool, $\alpha$ and $\beta$ are changing, but $\gamma$ is unchanged, because magnetic sensor has the advantages of quick response and hardly being affected by vibrations, when the drill tool is rotating, it can get good measurement results, and the direction of the measuring window can be got. The relationship of $\alpha, \beta$, and $\gamma$ is shown in Figure 2 .

In the well, the measurement window's position can be divided into three zones: high side, low side, side area. When the angle between measurement window and the gravitational vector is within $\pm 30^{\circ}$, it is considered to be the low side; When the angle between measurement window and the opposite direction of the gravity vector is within $\pm 30^{\circ}$, it is considered to be high side; the else situation is side area, as is shown in Figure 3. 


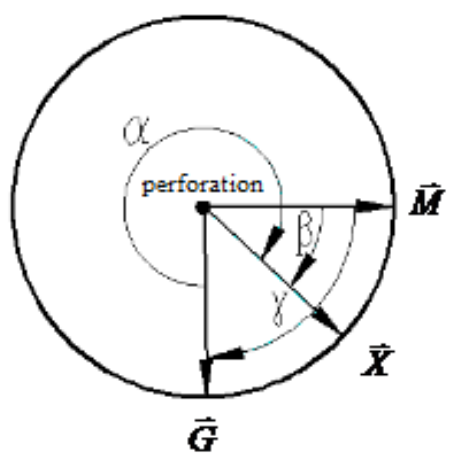

Figure 2. The relationship of $\alpha, \beta \& \gamma$.

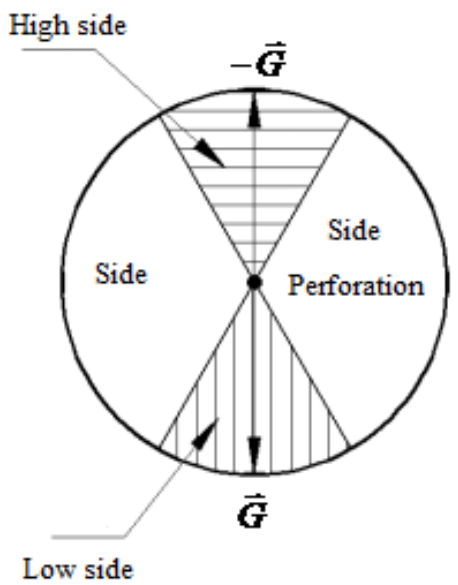

Figure 3. The division of detection range.

\section{Oil Reservoir Boundary Identification Method}

Natural radionuclides tend to be concentrated in the clay and mud stone formation, the clean formation usually contains a very small amount of radioactive material, so the Oil reservoir is less radioactive than clay and mud stone formation, the Gamma detector counts less as well. Azimuth Gamma Ray logging tool is used by rotating the drilling tools to scan and detect the gamma ray which are around the borehole wall. As can be seen from Figure 4, When the drilling tool is in the middle of the reservoir, the average gamma value and the gamma value of high side and low side are almost the same; when the drilling tool is approaching the upper boundary of the reservoir, high side gamma value rises first, low side and the average gamma value also rise, but not so fast as high side; when the drilling tool is approaching the lower boundary of the reservoir, low side gamma value rises first, high side and the average gamma value also rise, but not so fast as low side. From this, we can identify the upper and lower boundary of reservoir by using variation tendency and sequencing of gamma value of the high side and low side.

\section{Design of System Hardware}

MSP430F149, an enhanced 16-bit MCU produced by TI Company, is selected as the control core. The device features a large memory space, various interfaces, ISP capabi- 

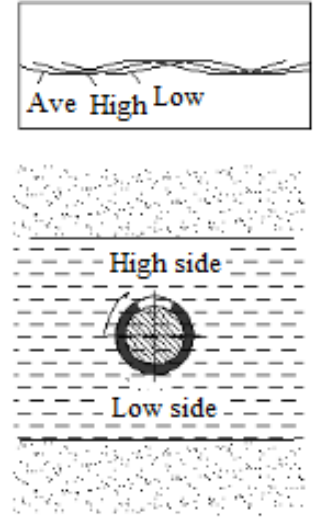

Reservoir Center
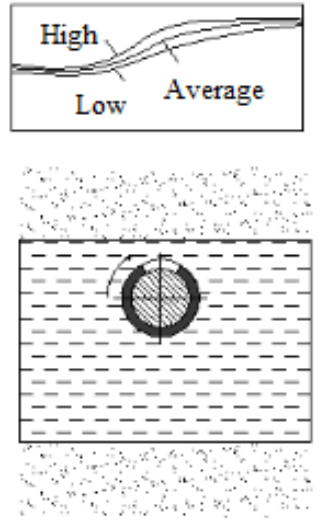

Upper boundary of reservoir
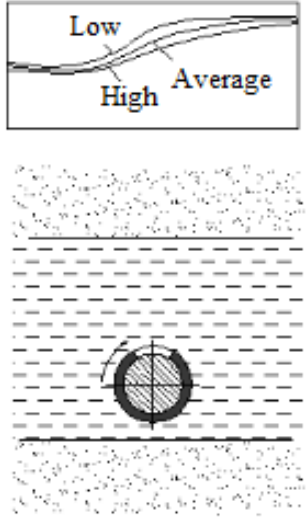

Lower boundary of reservoir

Figure 4. Reservoir boundary identification method.

lity, and a wide operating temperature range of $-40-125$ degree Celsius, all of which perfectly satisfy the requirement of the down-hole environment.

ADS1216, a successive approximation Analog-to-Digital converter (ADC) produced by Analog Devices, Inc., with 24-bit resolution and 8 input channels, is selected as the A/D module for signal acquisition. The device has a combined features of broadband input, low power, high precision, high integration, and a wide temperature range of -40 - 125 degree Celsius. Data transmission between ADC and MCU is realized through the serial peripheral interface (SPI), while MCU receives and transmits orders through the serial communication interface (SCI).

The overall system is composed of the following parts: the sensor module, amplifier circuit, filter circuit, analog-to-digital conversion and single-chip microcomputer circuit, etc. With the application of modular design, the system is open to debugging and maintenance. The whole system block diagram is shown in Figure 5.

\section{Design of System Software}

In order to assure the efficiency, readability and portability of the procedures, the system adopts $\mathrm{C}$ as its programming language. With the help of the ISP function on the MSP430F149 chip, it becomes more convenient either to write codes into MCU through the USB port, without getting devices off the PCB board, or to modify the programs downloaded to MCU in real-time just under the PC environment. The system flow chart and error compensation flow chart are both shown in Figure 6.

\section{Experiment Result Analysis}

The experiments of Tubular Azimuth Gamma Ray logging tool include the calibration experiment of Angle sensors, the calibration experiment of the gamma detector and the down-hole experiment. The calibration experiment of Angle sensors requires that the accuracy of magnetic tool-face and gravity tool-face reach 1.5 degree. The calibration experiment of the gamma detector needs to calibrate the average gamma value in API, 


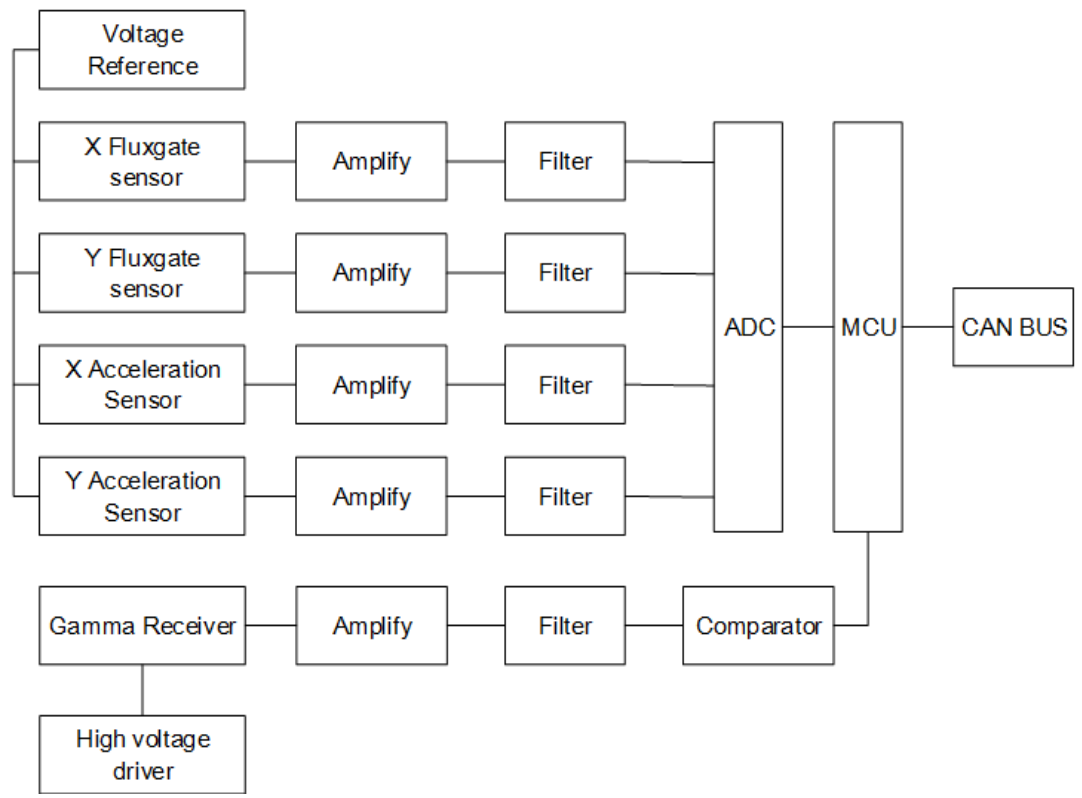

Figure 5. Block diagram of the system.

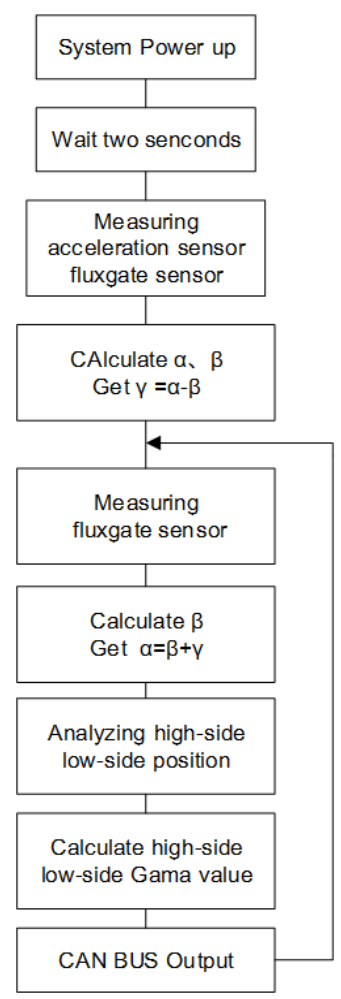

Figure 6. System main program flow chart.

and the down-hole experiment can test logging tool's reservoir recognition ability comprehensively. Figure 7 is LWD azimuth gamma chart of NANYANG oil field. The red line is high side gamma, the black line is average gamma, the green line is low side gamma, when drilling tool working in the reservoir, the high-side, low-side and average 


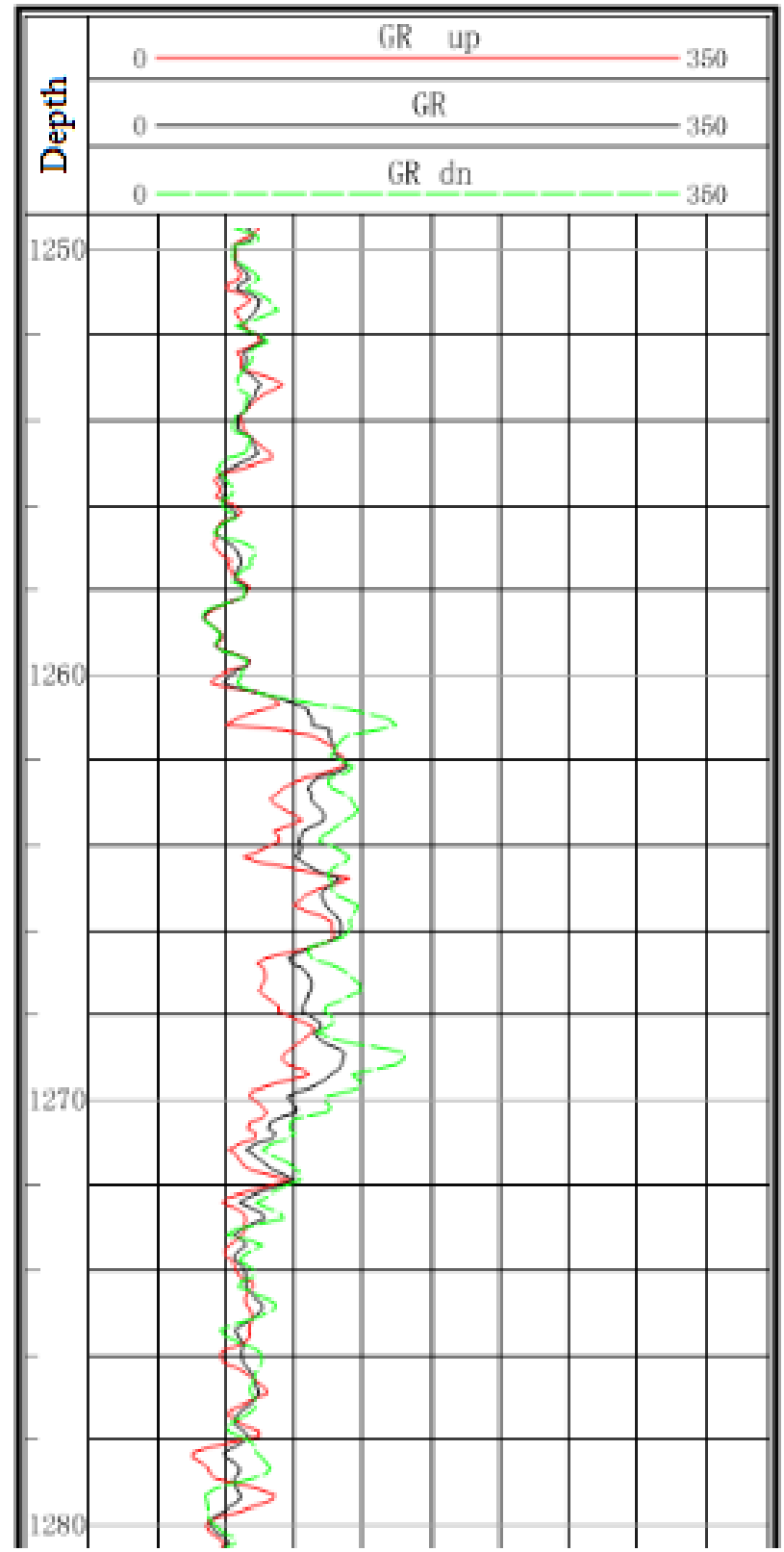

Figure 7. System main program flow chart.

gamma are almost the same, such as 1250 - 1260 meter of depth in the curve. The value of three gamma increase at the same time at the depth of $1260-1262$ meter, but low side gamma is the first one to increase, and the value is the largest of all, therefore, it can be estimated that the drilling tool has been moving out of the reservoir and into the mud from the low side; Then drilling tool has been moving in mud at the depth of 1262 - 1269 meter. The value of three gamma decrease at the same time at the depth of 1269 - 1272 meter, but the high side gamma is the first one to decrease, and the value is smallest of all, it can be estimated that the drilling tool has been moving out of the mud and into the oil layer from the low side of the reservoir. 


\section{References}

[1] Sinopec Shengli Petroleum Administrative Bureau Drilling Technology Research Institute (1997) Inclination and Azimuth Gamma MWD Instrument. China Patent: 200510043226.4.

[2] Lin, Z.Q., Hao, Y.L. and Zhang, G.L. (2008) Apply the Azimuth Gamma LWD for the Horizontal Well Orientation in Jidong Oilfield. Mud Logging Engineering.

[3] Wu, Z.H. (2011) New Technology about Geological Orientation of Near-Drill Bit Azimuth Gamma Ray Imaging Tool in the Thin Reservoir. Well Logging Technology.

[4] Tang, Y. (2012) Azimuth Gamma of MWD Optimization of Shale Oil and Gas Detection. Well Logging Technology.

\section{Submit or recommend next manuscript to SCIRP and we will provide best service} for you:

Accepting pre-submission inquiries through Email, Facebook, LinkedIn, Twitter, etc. A wide selection of journals (inclusive of 9 subjects, more than 200 journals)

Providing 24-hour high-quality service

User-friendly online submission system

Fair and swift peer-review system

Efficient typesetting and proofreading procedure

Display of the result of downloads and visits, as well as the number of cited articles Maximum dissemination of your research work

Submit your manuscript at: http://papersubmission.scirp.org/

Or contactwjet@scirp.org 